\title{
Editorial from the Editor in Chief: Conferences related to Laser and Particle Beams
}

With the second issue of volume 25, Laser and Particle Beams has published 20 articles related to the topic of intense beams interacting with matter and related applications. One of the most outstanding future applications of this research field is inertial fusion energy. The prospects of energy from inertial fusion have initiated many research projects and Laser and Particle Beams frequently carry articles on this topic and related subjects (Hora, 2004, 2007; Leon et al., 2005; Miley et al., 2005; Bret \& Deutsch, 2006; Perlado et al., 2005; Someya et al., 2006; Imasaki \& Li, 2007). This year, September 9-14, the Fifth International Conference of Inertial Fusion Science and Applications (IFSA 2007) will be held in Kobe, Japan. Many authors and readers of Laser and Particle Beams plan to attend, and will use the opportunity to meet with fellow scientists to discuss the progress in inertial fusion science. There has been a tremendous development in recent years in all fields that are related to this topic. Two larger laser facilities are under construction; these two are the National Ignition Facility (NIF) in Livermore, California and the Megajoule Project at Bordeaux in France. From both laboratories, the journal has frequent contributions about the progress of the field (Nobile et al., 2006; Lontano et al., 2006; Chen \& Wilks, 2005; Kilkenny et al., 2005; Ng et al., 2005; Mangles et al., 2006; Borghesi et al., 2005; Breil et al., 2005; Fernandez et al., 2005).

These articles are just an example of many research projects in recent years related to inertial fusion. The development in target production is one key issue in this field. Russian and United States laboratories have made outstanding contributions to the target technology (Kilkenny et al., 2005). High energy density science, which can be regarded as an offspring of inertial fusion science, has experienced a boost due to the remarkable technical achievements in laser technology. In addition, pulsed power has experienced dramatic progress toward inertial fusion. The Z-machine at Sandia National Laboratories in Albuquerque, New Mexico, is a very good example. Moreover, this laboratory uses a high intensity laser along with the Z-machine, where the laser serves diagnostic purposes. A similar development is going on at Gesellschaft für Schwerionenforschung
Darmstadt, Germany, where the PHELIX laser system, a high intensity laser with petawatt capabilities will be used in conjunction with the high intensity heavy ion beam to generate, and study examples of warm dense matter. In many laboratories worldwide, high intensity laser and ion beams, as well as pulsed power are used to address high energy density physics, which is a basis for understanding the complicated processes matter undergoes during the compression heating and compression phase in an inertial fusion target (Jungwirth, 2005; Batani et al., 2007; Danson et al., 2005; Hoffmann et al., 2005; Temporal et al., 2005; Becker et al., 2006; Barriga-Carrasco Maynard, 2005; Ng et al., 2005).

In 2006, there was a small workshop at the Korea Advanced Institute of Technology devoted to the problems and application of simulated Brillouin scattering. One important application related to the topic of inertial fusion is the prospect for high repetition rate lasers of high intensity using Brillouin scattering phase conjugate mirrors. Important results that originated from the discussion during this workshop are carried in this and previous issues of Laser and Particle Beams (Kappe et al., 2007; Meister et al., 2007, Wang et al., 2007; Kong et al., 2006).

Finally, I want to address the performance of Laser and Particle Beams. In the section called essential science, indicators the ISI web of knowledge the top papers for journals that are recognized by this index evaluation are listed. This section includes only those papers that meet a certain citation threshold specific to the field and year. For our Journal, seven recent papers are listed (Hora, 2004, 2005; Hoffmann et al., 2005; Roth et al., 2005; Badziak et al., 2005; Schaumann et al., 2005; Glowacz et al., 2006). In June of 2007, when this issue appears, the new impact factors of journals will be published, and we expect for the third year in a row a remarkable increase of this essential indicator.

\section{REFERENCES}

Badziak, J., Glowacz, S., Jablonski, S., Parys, P., Wolowski, J. \& HorA, H. (2005). Laser-driven generation of high-current ion 
beams using skin-layer ponderomotive acceleration. Laser Part. Beams 23, 401-409.

Barriga-Carrasco, M.D. \& MaYnard, G. (2005). A 3D trajectory numerical simulation of the transport of energetic light ion beams in plasma targets. Laser Part. Beams 23, 211-217.

Batani, D., Dezulian, R., Redaelli, R., Benocci, R., Stabile, H., Canova, F., Desai, T., Lucchini, G., Krousky, E., Masek, K., Pfeifer, M., Skala, J., Dudzak, R., Rus, B., Ullschmied, J., Malka, V., Faure, J., Koenig, M., Limpouch, J., Nazarov, W., Pepler, D., Nagai, K., Norimatsu, T. \& Nishimura, H. (2007). Recent experiments on the hydrodynamics of laser-produced plasmas conducted at the PALS laboratory. Laser Part. Beams 25, 127-141.

Becker, F., Hug, A., Forck, P., Kulish, M., Ni, P., Udrea, S. \& VARENTSOV, D. (2006). Design, development, and testing of nonintercepting profile diagnostics for intense heavy ion beams using a capacitive pickup and beam induced gas fluorescence monitors. Laser Part. Beams 24, 541-551.

Borghesi, M., Audebert, P., Bulanov, S.V., Cowan, T., Fuchs, J., Gauthier, J.C., MacKinnon, A.J., Patel, P.K., Pretzler, G., Romagnani, L., Schiavi, A., Toncian, T. \& Willi, O. (2005). High-intensity laser-plasma interaction studies employing laserdriven proton probes. Laser Part. Beams 23, 291-295.

Bret, A. \& Deutsch, C. (2006). Density gradient effects on beam plasma linear instabilities in axisymmetric geometry self-similar models and numerical simulations. Laser Part. Beams 23, 269-273.

Breil, J., Hallo, L., Maire, P.H. \& Olazabai-Loumé, M. (2005) Hydrodynamic instabilities in axisymmetric geometry selfsimilar models and numerical simulations. Laser Part. Beams 23, 155-160.

Chen, H. \& WiLks, S.C. (2005). Evidence of enhanced effective hot electron temperatures in ultraintense laser-solid interactions due to reflexing. Laser Part. Beams 23, 411-416.

Danson, C.D., Brummitt, P.A., Clarke, R.J., Collier, J.L., Fell, B., Frackiewicz, A.J., Hawkers, S., Hernandez-Gomez, C., Holligan, P., Hutchinson, M.H.R., Kidd, A., Lester, W.J., Musgrave, I.O., Neely, D., Neville, D.R., Norreys, P.A., Pepler, D.A., Reason, C.J., Shaikh, W., Winstone, T.B., Wyatt, R.W.W. \& Wyborn, B.E. (2005). Vulcan petawatt: Design, operation and interaction at $5 \times 10^{20} \mathrm{Wcm}^{-2}$. Laser Part. Beams 23, 87-94.

Fernandez, J.C., Hegelich, B.M., Cobble, J.A., Flippo, K.A., Letzring, S.A., Johnson, R.P., Gautier, D.C., Shimada, T., Kyrala, G.A., Wang, Y.Q., Wetteland, C.J. \& Schreiber, J. (2005). Laser-ablation treatment of short-pulse laser targets: Toward an experimental program on energetic-ion interactions with dense plasmas. Laser Part. Beams 23, 267-273.

Glowacz, S., Hora, H., Badziak, J., Jablonski, S., Cang, Y. \& Osman, F. (2006). Analytical description of rippling effect and ion acceleration in plasma produced by a short laser pulse. Laser Part. Beams 24, 15-25.

Hoffmann, D.H.H., Blazevic, A., Jablonski, S., Cang, Y. \& Osman, F. (2006). Analytical description of rippling effect and ion acceleration in plasma produced by a short laser pulse. Laser Part. Beams 24, 267-273

Hora, H. (2004). Developments in inertial fusion energy and beam fusion at magnetic confinement. Laser Part. Beams 22, 439-449.

Hora, H. (2007). New aspects for fusion energy using inertial confinement. Laser Part. Beams 25, 37-45.
IMASAKI, K. \& Li, D. (2007). An approach to hydrogen production by inertial fusion energy. Laser Part. Beams 25, 99-105.

Jungwirth, K. (2005). Recent highlights of the PALS research program. Laser Part. Beams 23, 177-182.

Kappe, P., Strasser, A. \& Ostermeyer, A. (2007). Investigation of the impact of SBS-parameters and loss modulation on the model locking of an SBS-laser oscillator. Laser Part. Beams 25, 107-116.

Kilkenny, J.D., Alexander, N.B., Nikroo, A., Steinman, D.A., Nobile, A., Bernat, T., Cook, R., Letts, S., Takagi, M. \& Harding, D. (2005). Laser targets compensate for limitations in inertial confinement fusion drivers. Laser Part. Beams 23, 475-482.

Kong, H.J., Yoon, J.W., Shin, J.S., BeAK, D.H. \& LeE, B.J. (2006). Long term stabilization of the beam combination laser with a phase controlled stimulated Brillouin scattering phase conjugation mirrors for the laser fusion driver. Laser Part. Beams 24, 519-523.

Koresheva, E.R., Osipov, I.E. \& Aleksandrova, I.V. (2005). Free standing target technologies for inertial fusion energy: Target fabrication, characterization, and delivery. Laser Part. Beams 23, 563-571.

Leon, P.T., Eliezer, S., Piera, M. \& Marinez-Val, J.M. (2005). Inertial fusion features in degenerate plasmas. Laser Part. Beams 23, 193-198.

Lontano, M., Passoni, M., Riconda, C., Tikhonchuk, V.T. \& WEBER, S. (2006). Electromagnetic solitary waves in the saturation regime of simulated Brillouin backscattering. Laser Part. Beams 24, 125-129.

Mangles, S.P.D., Walton, B.R., Najmudin, Z., Dangor, A.E., Krushelnick, K., Malka, V., Manclossi, M., Lopes, N., Carias, C., Mendes, G. \& Dorchies, F. (2006). Table-top laserplasma acceleration as an electron radiography source. Laser Part. Beams 24, 185-190.

Meister, S., Riesbeck, T. \& EICHLER, H.J. (2007). Glass fibers for stimulated Brillouin scattering and phase conjugation. Laser part. Beams 25, 15-22.

Miley, G.H., Hora, H., Osman, F., Evans, P. \& Toups, P. (2005). Single event laser fusion using ns-MJ laser pulses. Laser Part. Beams 23, 453-460.

Ng, A., Ao, T., Perrot, F., Dharma-Wardana, M.W.C. \& Foord, M.E. (2005). Idealized slab plasma approach for the study of warm dense matter. Laser Part. Beams 23, $527-537$.

Nobile, A., Nikroo, A., Cook, R.C., Cooley, J.C., Alexander, D.J., Hackenberg, R.E., Necker, C.T., Dickerson, R.M., Kilkenny, J.L., Bernat, T.P., Chen, K.C., Xu, H., Stephens, R.B., Huang, H., HaAn, S.W., Forsman, A.C., Atherton, L.J., LetTs, S.A., Bono, M.J. \& Wilson, D.C. (2006). Status of the development of ignition capsules in the US effort to achieve thermonuclear ignition on the national ignition facility. Laser Part. Beams 24, 567-578.

Perlado, J.M., Sanz, J., Velarde, M., Reyes, S., Caturla, M.J., Arevalo, C., Cabellos, O., Dominguez, E., Marian, J., Martinez, E., Mota, F., Rodriguez, A., Salvador, M. \& Velarde, G. (2005). Activation and damage of fusion materials and tritium effects in inertial fusion reactors: Strategy for adequate irradiation. Laser Part. Beams 23, 345-349.

Roth, M., Brambrink, E., Audebert, P., Blazevic, A., Clarke, R., Cobble, J., Cowan, T.E., Fernandez, J., Fuchs, J., Geissel, M., Habs, D., Hegelich, M., Karsch, S., Ledingham, K., Neely, D., 
Ruhl, H., Schlegel, T. \& Schreiber, J. (2005). Laser accelerated ions and electron transport in ultra-intense laser matter interaction. Laser Part. Beams 23, 95-100.

Schaumann, G., Schollmeier, M.S., Rodriguez-Prieto, G., Blazevic, A., Brambrink, E., Geissel, M., Korostiy, S., Pirzadeh, P., Roth, M., Rosmej, F.B., Faenov, A.Y., Tsigutkin, K., Maron, Y., TahiR, N.A. \& Hoffmann, D.H.H. (2005). High energy ion jects emerging from laser plasma generated by long pulse laser beams from the NHELIX laser system at GSI. Laser Part. Beams 23, 503-512.
Someya, T., Miyazawa, K., Kikuchi, T. \& Kawata, S. (2006). Direct-indirect mixture implosion in heavy ion fusion. Laser Part. Beams 24, 359-369.

Temporal, M., Lopez-Cela, J.J., Piriz, A.R., Grandjouan, N., TAhiR, N.A. \& Hoffmann, D.H.H. (2005). Compression of a cylindrical hydrogen sample driven by an intense co-axial heavy ion beam. Laser Part. Beams 23, 137-142.

WANG, S.Y., Lu, Z.W., Ding, L. \& JiANG, D.B. (2007). Investigation of serial coherent laser beam combination based on Brillouin amplification. Laser Part. Beams 25, 79-83. 